\title{
Controversial Reflections on the Theme "Leisure": from Free Time to Lifestyle
}

\author{
Bohuslav Hodan, Donald N. Roberson Jr.
}

Faculty of Physical Culture, Palacky University, Olomouc, Czech Republic

ABSTRACT

Today there is more of a dialectical approach to the meanings of leisure. In earlier times there was more of a consensus or similar understanding of one's free time. The purpose of this paper is to explain today's various meanings of leisure. We discuss the meaning of time and space and its relation to leisure. In addition we have focused on a discussion of free time, work and not work, as well as one's lifestyle. In particular we will introduce the ideas of Dumazedier. In summary we concur with other authors, especially Dumazedier, that leisure is more than free time: it is best understand as a way of life, as a lifestyle.

KEYWORDS $\quad$ approaches, time space, Dumazedier, lifestyle

Studying the literature concerning "leisure" or "free time", we can find two parallel directions. On one side for many years there existed identical or similar understandings of leisure, on the other side, a recent doubting about this term.

\section{Introduction}

At the beginning we refer to the difference between "leisure" and "free time" - "free time" is more general than "leisure", which is its possible variant. If we have to deliberate about "leisure", it is needed, at least briefly, to perceive the general problem of "time." This is not meant to investigate different philosophical theories of this subject and their comparisons, but to put in opposition some thoughts about "time" and "leisure." This is why it is appropriate, for comparison, to introduce some known views, historically and considerably distant from one another. For example, Aristotelés (1996a) theorizes that time is calculated movement in view of before and after, Plótínos (1995) understands time as the life of soul in motion, Augustinus (1990) thinks that time cannot be anything other than a spread of moments, but he does not know spread of which, maybe of the soul itself.

\section{Time}

In this modern age, time was perceived as something absolute, or as something ideal, what is not found in reality (Newton 1990). Kant (2001) speaks about time as the form of a human's view, as about the sense of opinion. Patočka (1992) understands time as a united function of expectation, sighting and retention of existence. It is evident that, beyond the different approaches of these introduced authors, they have something in common. By the concept "time", which seems difficult to 
understand, the "space", without some further specifying, is delimited. Evidently it involves the "space", which can be randomly manipulated, or in which something may be placed. In these consequences we apologize for the choice of the term "space", because philosophically it has other character.

"Space" can only be between some "bodies", this "space" is enclosed by them, and the "speed of motion" of these bodies is measured by "time". So, "time space" can be understood as a helping fiction. But "time" or this "time space" is also what was, is, and will be. This is from the point of view of our individual life rather what was and will be. So that time is what permanently flows, what we cannot detain and also generally have not.

Of course, the majority of us perceive "time" practically as an abstract expression of something we have, or don't have, at our disposition, for something concrete to carry out. So, time can be seen as the "space" for carrying out concrete activity, or the "space" to fulfill by inactivity. "Time", in this interpretation, becomes the abstract "space", or even an abstract possibility related to concrete activity or inactivity. But, out of the fundamental philosophical interpretation of "time", and from the relation of "time" to the human's practical activity, results in its sociological interpretation.

One of the interesting studies concerning the sociological conception of time is Subrt’s (1993) studies. In the introduction he says that:

"By influence of education, which we have took, the majority of us understand time as something what is purely quantitative, without features, evenly, constantly and unchangingly - second per second-flowing, shortly like some unsubstantial form, or like one of abstract ordinates, in which our life and consequent phenomena we measure. It is a conception resulting from Newton's view of the world..."

\section{(Šubrt 1993, p. 99).}

This opinion, resulting from an understanding of time like "space" for activity, is not so simple, and it evolves into a few dimensions. "Time" is a conception that reflects infinity and boundlessness. "Time" was, is, and will be without regard to us. Of course, "time" is also a conception that we had instituted to structure our activity. And in such viewing "time" there are fundamental differences. Farmers understood and until this time understand "time" in connection to changes of seasons or the rotation of day and night. These time periods, fluently crossing one into another, predestinated the rhythm of his activities and his life. From the point of view of the "rationalization" of our activity, this objective rhythmization was insufficient, so we had deduced from it the precise measure of time. So we are able to measure its flowing to the relation to our activity, to our life, not only second per second, but infinitely more precisely.

So it happened that "time", like infinity, changed into something finite, into something that has its beginning and its end, and has a different length. And this "length" of time is this "space" which we have to our disposition, which we fulfill by our activity. The measure of this length serves to us as orientation points, but "length" of time is, in the same way, individually different. Understandably, it is not "length" objectively measured, but subjectively perceived. Surely, this is not resulting only from our subjective perceiving, caused by the power of our experiences connected with our activity. It is connected also with change of speed and the deceleration of the physiological processes in relation to our age. So, on one side time is the expression of infinity, on the other side, in relation to concrete individual, it is the expression of finiteness. It is, in its substance, given by nascence and death. It is that concrete space, which has the concrete human at his disposition. Flow of time in these limits, the speed of its run, and the disappearance of disposable space, is heterogeneous and relative to the concrete events.

Understandably, we can in these and similar considerations continue further, but it is not the object of this paper. But it results from it that to the concept "time", in respect to this what it expresses, we can hardly add more adjectives and so distinguish one time from other. 


\section{Free time}

In the aforementioned paper, Šubrt (1993), on the basis of studies of some papers of a few authors, assigns to "time" different functions. He speaks about "time" as an expression of collective life rhythm, or the formal condition of socialization, about the relation of constitution of time and human dealing, about the social sense of time and its structure and level, and about the task of time in the system theory and social theory. It seems to us, that this approach is more acceptable than the attempts to part "time" in different kinds.

From this general consideration we can pass to the problem of "free time". Why is the term "time" added to some adjectives, and "free time" is by this way generally detached from "time"? We suppose that, before all, it is the problem of the organization of society and work of the predominant number of people. In the past the structure of society and work and with it connected its organization was, during long decades or even centuries, unchanging. Surely, it is not possible to say the same about contemporary society.

The term "free time" or "leisure" is not a new term. But in this contemporary, hectic society it appears like every mounting problem. The first mentions are known from ancient society and they are connected with the volume of the known term "scholé" (Aristotelés 1996b).

It is to say that the majority of present opinions and definitions result from the French sociologist Dumazedier (1962). He conceived "free time" as a complex of activities except work, family, and social obligations. These are the activities which a human realizes from its volition and which are targeted to relaxation, entertainment, or to the free perfection of his creative capacity. It is interesting that this conception goes outside any expression of "time", explicitly (anticipated) "space", but promptly this supposes that "space" is fulfilled by the complexity of activities. But these activities have, for the human being, non-obligatory character; they result from his free decision, without relationship to any duty. The direction of these activities is for regeneration, entertainment and personal development. This is a basic characteristic, from which dozens of further meanings result. It corresponds evidently to the character of the era from which it originated. It corresponds, before all, to the technological development, from which all others unreel. To this era corresponds, for the absolute majority of people, a precise definition of working time without the possibility of any change its borders.

Fundamental discrepancies between work versus not-work, work versus relaxation, and work versus enjoyment are evident. Understandably, the characteristic of corresponded social roles is connected with it. With respect to these and other discrepancies, it is comprehensible that in the majority of people there has originated a precise bordered "time distances" like "spaces" for the activities of an absolutely distinct character. Working activity is possible to consider as a firm, given time, terminable, and giving economic profit. Thus, the human is de facto economically obliged to perform these engagements. Family engagements have another character. Even if they are accepted by the majority of people, they are based on a free decision to establish the family and to accept corresponding engagements. But their performance has other character than the performance of working engagements, and they are not attached to any economic effect.

Social engagements are also not attached with economic effect, but mainly, only by the minor part of population, they are more or less directly attached with the social role. Vice versa, these engagements are perceived by the absolute majority of the population as absolutely free, on the basis of free decision. That way, the author arranges to the antithesis of respective "free time" against all these engagements, the activities realized, he considers as absolutely free, aimed at relaxation, entertainment, respectively, to the development of its own capacity. But it is even here where the comprehensible questions originate: Is it really my decision to relax free, if it is in fact a physiological necessity? Is my decision to develop my own creative capacity a free one, or is it, in relation to my duty, corresponding to my social role? 
In this present time we can find two hundred definitions of "free time". The majority of them are derived from Dumazedier's (1962) definition. From their analysis there results an evolution of understanding of "free time" in distinctly two directions. First, it is possible to say continuing in Dumazedier's line, which it copies, or more or less develops. But, in its essence it is understood as residual time, for which it is important for free decision, personal development, and economical independence. The second direction, it seems to us less numerous, goes out of this line and, in contradiction to Dumazedier, brings some new possibilities. So, they appear as the new outlook, by which the original ones are doubted. Of course, by our opinion, it is positive and necessary. We agree in this moment with Pieper (1992), who considered free time as the inner state of soul.

\section{Work and not-work}

From what does this necessity of doubtfulness emerge and on what basis do they appear as new opinions? The human life, its structure and volume, concededly reacts to the changes of surroundings, social roles, and their volume. If we confront the separate societies - before-industrial, industrial, post-industrial, and informative - surely the fundamental differences, which touch the proper basis of life, are evident. To these related differences correspond, in connection with the discussed problem of "free time", a technological level and with this connected concept of work. From this emerges another structure of working activity - while in the past the majority of working activities were temporally and spatially limited, they come up, in the present time more and more, as the working activities semi-free and free. They are, otherwise, defined by specific concrete tasks, but its fulfillment emerges from the individual decision what, when, and where will be realized.

Thanks to all these changes, work is already not the only necessary and unpleasant duty, the result of which is obtaining resources for the satisfaction of necessary human needs. Work is more and more connected with enjoyable positive experiences and in many cases with a personal hobby. But, in contradiction to this, Dumazedier explains the positive experiences - enjoyments - are always connected only with "free time" and its definition. Up until now, "free time" is understood as the only possible space for personal development. It corresponds to the opinion that all activities in other times (outside of "free time") are aimed outside of the acting person, while the activities realized only in "free time" are aimed to the acting person, so, to care about himself.

But a new conception of work, namely of creative work, or of work like a hobby, offers at least the same space for individual development - the results of work and personal development are in mutual relations, they are mutually conditioned. From this point of view the antagonism between work versus not-work is vanishing. In this context it is suitable to introduce Blanchard's (1995, p. 46) illustration, which explains this relationship (figure 1).

Education is based on personal development, and surely, it is not the problem of "free time". So, in the case of the relationship between work and personal development there is the need to consider the difference between monotonous work of mechanic character and free creative work. With the development of technology it is evident that the mechanical, monotonous work is decreasing.

"Free time" is connected with free decision. But this free decision is markedly connected with free, creative working activities also. Though here also is a problem. Any decisions concerning the activities in "free time" may, and prevailingly they bring duty. This duty is connected with the realization of the free time activity, for which the human freely decided. Further, it becomes more important the more regular and more related to other people with which it is realized. 


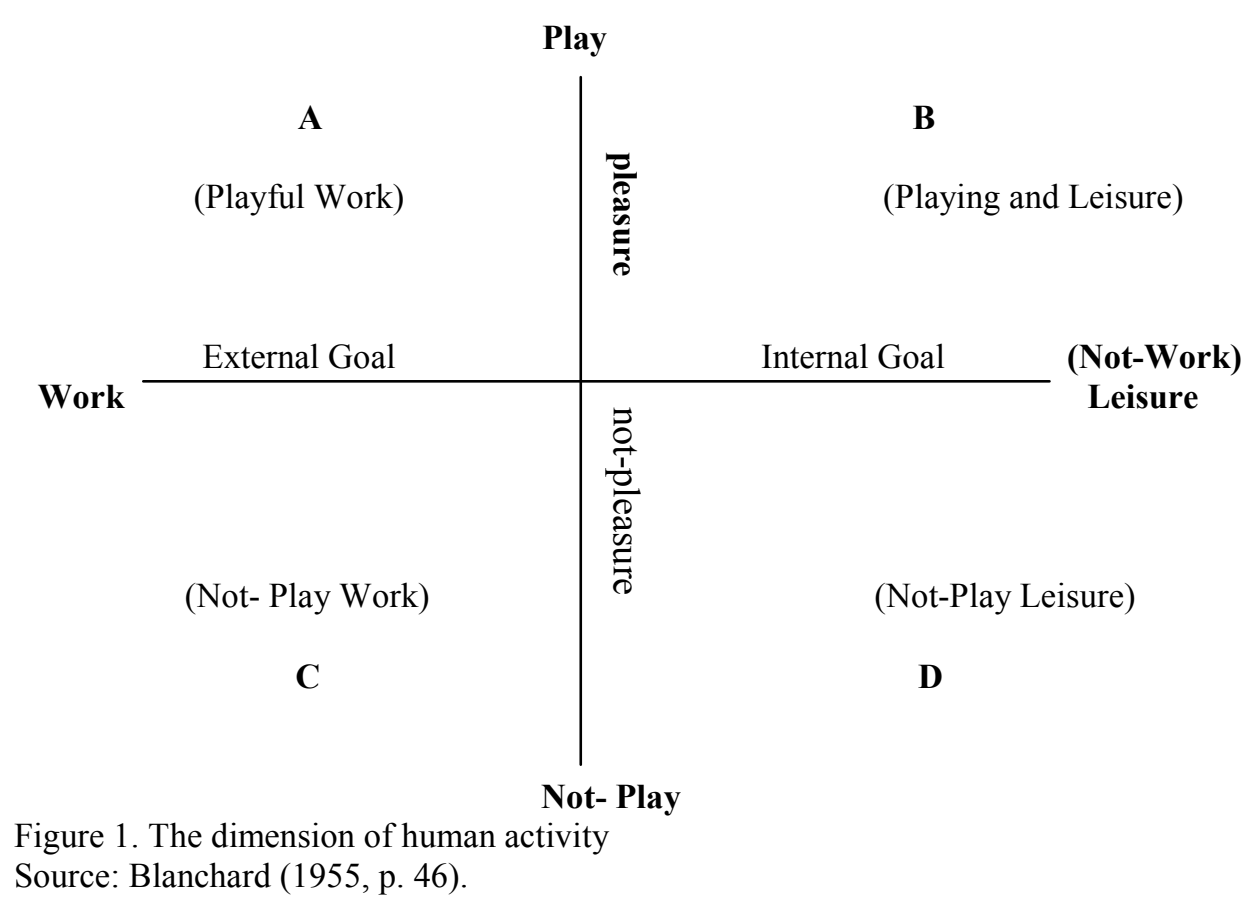

In many definitions, namely those which consider "free time" as residual time, is said that "free time" is free from all needs, including biological ones. But it is reduced only to these needs that are satisfied by the means required by a working activity. Of course, large amounts of biological, psychological, as well as social needs during these free time activities are satisfied. And namely they are biological needs, which penetrate through all our life, and it is not possible to refer them in one sphere only.

\section{Ideas of Dumazedier}

On the basis of this doubtfulness in which it would be possible to continue, there are further discrepancies and questions to formulate. They result in four statements, which are common for the majority of definitions derived from Dumazedier.

First Statement: Free time is free from all duties; free time is the only space for personal development. But if we proceed from the basic thesis that the human life, which has been given to all of us, is the highest value from which all others are deduced, then the basic human duty is to care about this value, to maintain and develop these values as our first duty. And this is not only for personal but for social benefit as well. It is possible to say that personal development is a basic human duty, so it is not from its essence dependent on free decision. Further, namely the biological needs we must not wish to satisfy during free time.

Second statement: Activities in free time are economically independent. But we have to add that these activities also bring an economic profit. The result of personal development is likewise a higher working performance, quality of work, reduction of sickness, and learning in leisure (Roberson 2005), which surely brings increase in economic effect. So, this mentioned independence does not apply totally. Or, for example, if two businessmen during their golf match negotiate a contract worth millions, is this free or working time? In both cases the so-called "free time" has as its consequence, even vicariously, an economic effect.

Third statement: "Free time" aims for relaxation and regeneration. The limited working time is interrupted by a rest period, by a social pause with coffee, or by exercising in a fitness center. Psychologists even recommend a daily short nap. It all is realized for the purpose of increasing the working performance during working time. Does it come to these activities on the basis of a "free decision", or on the basis of feeling that "I already need it"? And if these activities are realized during 
working time, are they free time activities? In this case, the discrepancy between "work" versus "relaxation" disappears - work is interrupted by periods of relaxation.

Fourth statement: Free time is that time which remains after the fulfillment of all duties associated with working and spare time. But, understandably, the structure of these times is different for working people based on their professional role, as well as retirees and pensioners. So, does free time concern only working people, or all people? Twenty years ago, in research (Hodaň 1988) oriented around problems of "free time" and "free time activities", it was ascertained that "free time" is not only what remains after working and not-working time. It was also confirmed in this research that the perception of free time is not objective, but a subjective category, conditional on individual and preferred needs. It is related to the fact that free time is generally conditional to gender, age, education, profession, and place of residence.

So, it is evident that the introduced discrepancies and original questions will vary by the social group, professional role, age, gender, and health. From many definitions we know that "free time" is given in opposition to other times - working and not-working. Through knowledge of the emerging discrepancies there results a new polarity: "indispensable time" versus "free time". But how is this "indispensability" characterized? Surely, it is highly differentiated for individuals. If we would like to specify the mutual space for "indispensability" for all members of the human species, we would arrive at the most basic biological needs. And surely, for understanding "free time", it would be much less. A similar polarity is also evident through the concepts of "available time" and "not-available time". From the point of view of conception of time and perception of time, it is possible to say that all time is available. So, the availability of time, or its opposite, is dependent on some perceived criteria again. In this manner we return again to the discrepancies and to the problems previously discussed.

From these aforementioned reasons it seems that "free time" is something not possible to comprehend, that it is not applicable as a concept, because it is not possible to define it precisely. Surely, in doubting this concept we could find many more reasons introduced in this deliberation. If we accept all the relations connected with "free time", if we accept its fundamental, absolutely individual causality, then it appears most similar to Pieper's (1992) expression that "free time" is the inner state of soul. Yet it has one disadvantage: this expression is possible to use in many further cases, because "the inner state of soul" is connected to many spheres of human life.

\section{Lifestyle}

That "inner state of soul" we would connect further. If we return to where we have started, it is evident that we all have our own life placed in fixed "time space", which has its origin and end. It is an individual space: "mine". This space can remain unfulfilled, or can be somehow fulfilled. "My" space is in the final consequence fulfilled only by "me" and cannot be influenced by surroundings or by relations between individuals and society. Regardless of this, if the effect of this fulfillment of "time space," so the effect of realized activities is individual or social. It is "my" space and "my" fulfillment of this space that is the concern. That is why the final effect is dependent on "my" approach, not only to "my" individual life, but also to "my" social life. This approach is based on the formulation of the sense of "my" life and its achievement. Corresponding to it are all considerations and all concrete activities, their variation and diffusion. Of course, all of this is expressed by the concept "lifestyle". Just as in the case of "free time" we could also in the case of "lifestyle" find and analyze the many definitions and characteristics.

Despite different approaches to the "lifestyle", it is evident that it is a:

a. historically set form of individual life, in which the human being reproduces his existence,

b. knowledgeable search and formation for qualitatively higher life forms and values, in which the best fully reflect the objective features of inter-individual relations. They are the expression of ideological, ethical and other approaches in human activity (Hodaň 2000). 
In such a characteristic "lifestyle" we can discover, in a general level, that the conditions of "lifestyle" and "free time" are the same. So what concerns "free time" is also a problem of "lifestyle". It seems that the problem of "free time" is included in the problem of "lifestyle". They are: individual development and its actual state; the cultural level of concrete individuality; individual philosophical and value orientation; family traditions; the specific participation in production process; membership of given professional group and one's position in it; the amount and level of realized social roles; the accomplished life standard of living; and the influence of one's surroundings. So if from these conditions the "lifestyle" emerges, its return impact on a human being is spontaneous and hazardous. But if it has to be individually useful, then the intervention, in the sense of its optimization, is needed. The result of this optimization is a re-evaluation, a change and shift of the activities by which "I" fulfill "my" time space. As we showed above, the borders between these activities are very inexact, contrary to the strict borders of "working time" - "not-working time" - "free time". It results from the aforementioned arguments that it goes this way, on the basis of different conditions, entirely individually based on the dominance of these or others activities. Furthermore, as the component of the individual lifestyle, these conditions can be judged from the point of view of "inner state of soul".

\section{Conclusion}

Regarding all these introduced discrepancies, as well as regarding the present state of civilization, it seems to us that the concept of "free time" is obsolete, and so, from our point of view, measurably unavailable. It seems that the concept "lifestyle" is a quite sufficient expression for all possibilities, which offers to us "time" in which our life proceeds. And understandably, it is a problem of values and preferences, which vary individually.

\section{REFERENCES}

Augustinus, A. (1990). Vyznání. Praha: Kalich.

Aristotelés (1996a). Fyzika. Praha: Petr Rezek.

Aristotelés (1996b). Etika Nikomachova. Praha: Petr Rezek.

Blanchard, K. (Ed.) (1995). The Anthropology of Sport. Westport: Bergin \& Garvey.

Dumazedier, J. (1962). Vers une civilisation de loisir? Paris: Editions du Seuil.

Hodaň, B. (1998). Physical culture and its role in creating and regenerating workforce. Acta Universitatis Palackianae Olomucensis, Gymnica, XVIII, 5-22.

Hodaň, B. (2000). Tělesná kultura - sociokulturní fenomén: východiska a vztahy. Olomouc: Univerzita Palackého.

Kant, I. (2001). Kritika čistého rozumu. Praha: OIKOYMENH.

Newton, I. (1990). Mathematical principles of natural philosophy. Chicago: Encyclopedia Britannica.

Patočka, J. (1992). Přirozený svět jako filozofický problem. Praha: Československý spisovatel.

Pieper, J. (1998). Leisure, the basis of culture. South Bend, IN: St. Augustie's Press.

Plótínos (1995). Věčnost, čas a duch. Praha: Petr Rezek.

Roberson, D. N., Jr. (2005). Leisure and learning: An investigation of older adults and self-directed learning. Leisure/Loisir, 29(2), 203-237.

Šubrt, J. (1993). Kategorie času v sociologii. In Kolektiv: Sociologické texty I (Sociological texts I) (pp. 99-107). Praha: Karolinum.

AUTHOR'S ADDRESS: $\quad$ Bohuslav Hodan Fakulta telesne kultury OP

tr. Miru 115, Olomouc

77140 Czech Rep.

Email: Hodan@ftknw.upol.cz 